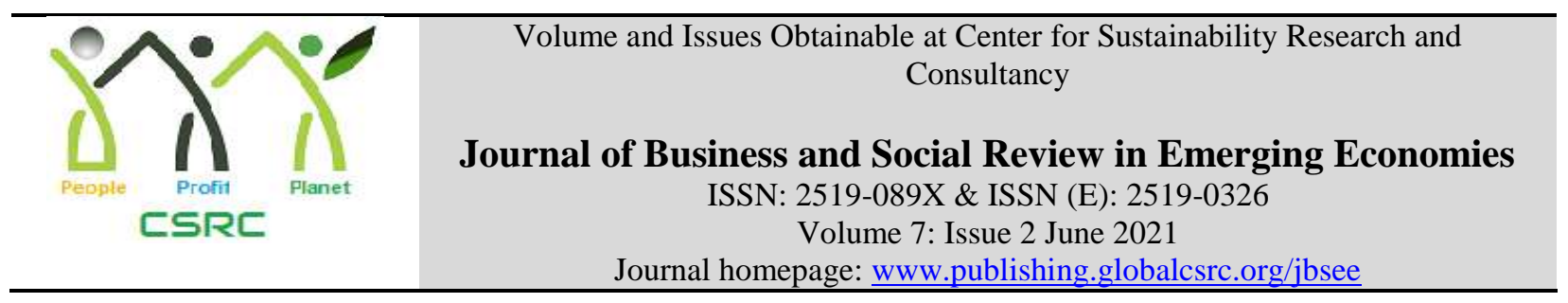

\title{
Expectations of PhDs Working in a Challenging School Environment: Results from a Qualitative Study
}

\author{
*Syed Abdul Waheed, Assistant Professor, Department of Educational Research \& Assessment, \\ University of Okara, Pakistan \\ Nadia Gilani, Assistant Professor, Department of Teacher Education, University of Okara, \\ Pakistan \\ Muhammad Saqib, Education Teacher, Center of Excellence, GHSS, Jaranwala, Pakistan
}

*Corresponding author's email: $\underline{\text { s.a.waheed@uo.edu.pk }}$

\begin{tabular}{l}
\hline ARTICLE DETAILS \\
\hline History \\
Revised format: May 2021 \\
Available Online: :Jun 2021
\end{tabular}

Keywords

PhD, School Teacher,

Expectations, School

Environment, Qualitative

study, Pakistan.

JEL Classification

IOO,I20

\begin{abstract}
Purpose: It is fortunate or unfortunate that PhDs are working as school teachers at different levels. It may be predicted that many $\mathrm{PhD}$ degree holders will be ready to join the School Education Department in near future while many candidates are completing their PhDs. The present study purports to explore expectations of PhDs working as school teachers and exploring the challenges they face while teaching in various schools of Sahiwal Division, Pakistan. Design/Methodology/Approach: Participants' lived experiences of working in schools were examined through the phenomenological approach of qualitative research. For this purpose, eleven $\mathrm{PhDs}$ were approached through a snowball sampling to gather data on the phenomenon employing the interviews. Findings: The results emerged in the form of themes and sub-themes that include relationships with the school community, $\mathrm{PhD}$ teachers' expectations (sub-themes: expectations from students and colleagues, expectations from education authorities, and expectations for professional development), and challenging school environment.

Implications/Originality/Value: The study implies the recognition of $\mathrm{PhDs}$ working as school teachers, their professional satisfaction, service structure and appropriate placement in the education system
\end{abstract}

(C) 2021 The authors, under a Creative Commons AttributionNonCommercial 4.0

Recommended citation: Waheed, S. A., Gilani, N. and Saqib, M. (2021). Expectations of PhDs Working in a Challenging School Environment: Results from a Qualitative Study. Journal of Business and Social Review in Emerging Economies, 7 (2), 255-264

\section{Introduction}

$\mathrm{PhD}$ degree holders are increasing in Pakistan, which led them to work in schools due to scarcity of job opportunities in higher education institutions for many PhDs in the country. There are 387 PhDs working in the School Education Department (SED) which is $0.11 \%$ of 367735 registered 
teachers in Punjab, the province of Pakistan (Government of the Punjab, School Education Department, 2020). There are clear chances for further increase of $\mathrm{PhD}$ graduates in schools because many $\mathrm{PhDs}$ are in progress and many other $\mathrm{PhDs}$ are ready to join schools in the upcoming recruitments if they could not get a chance for recruitment in the higher educational institutes. PhDs' challenges while working in schools include low financial benefits, low pay scales, recognition, further research grants, and attractive job opportunities. Their utilization in schools and appropriation with respect to their $\mathrm{PhD}$ subject may also be a challenge in the future.

According to Wing (2018), more than 2.9 million people in the United States have PhDs, half of them teach in colleges and universities, most do a part-time job, and less than a quarter of them have tenure-track positions. Even tenure-track opportunities are declining in academics, and they rely on low wages or temporary contracts. There are also thousands of PhD students in the pipeline in the United States of America.

Universities are producing more $\mathrm{PhDs}$, but there are few job opportunities for them. If one undergraduate student gets a $\mathrm{PhD}$ degree under the supervision of a university faculty member, then the ratio is $(1: 1)$, but the current ratio is (8:1) in most of the science and engineering departments. In other words, a university faculty member is producing eight PhDs. "The repurposed PhD" published in the New York Times and written by Tuhus-Dubrow (2013) reports an alarming situation about the financial careers of PhDs. Finding a teaching position in a school is easy compared to finding a teaching position in a university in Pakistan. Therefore, another option for PhDs is to join a school for teaching, and they can easily continue their research project in the university with their ongoing school job.

On the other hand, a PhD degree holder teacher can enjoy tenure track jobs as a visiting faculty member, a researcher in the research projects and a K-12 teacher at a school in the USA. PhD teachers can see their students be a co-author of their research after some years. School teachers have a resource, curiosity of knowledge, three breaks like summer break, winter break, spring break, and professional development trips and training. A PhD teacher can take research grant more easily as compared to other graduate students of the university. School teacher can earn more as compared to university job, and it depends upon geography. Most of the schools offer a good salary with retirement benefits. Job securities in schools are more than tenure track jobs of the university (Gilani et al., 2020; Wing, 2018).

Teacher's research is usually based on inquiry and assumptions revolving in their minds on which teacher decides to change or improve their practices. It can be action research and sometimes case study research. Sometimes, it refers to a self-study of a teacher or learning by collaborative discussions through the community network. Development in teaching methodologies, curriculum improvement is the result of teachers' participation in the research. No curriculum development process is successful without the participation of teachers (Craig, 2009).

Without research and innovation, the teaching and learning process discourages like an interviewee comments that "My school is doing nothing at all with research. They spend as little time as possible on the professional development of teachers. Dedicated hours for the professional development of teachers are not utilized. Meanwhile, nothing is done with research" (Bakx et al., 2016). There are many similarities that can be observed between teacher and researcher. With the help of research, many teachers are increasing their learning practices. Hence teaching and learning process is a research-based phenomenon. The value of research work is based on its significance. Schools are significant in society because they provide the necessary primary education or basic life skills to humans. Now in Pakistan, PhD degree holder teachers are doing a job in schools and higher education institutes/departments (HEI/HED). Their presence in the school education system is a different phenomenon than other routine teaching staff in schools. 
The empowerment and development of a society depend upon the standard of quality of education. The standard in education further refers to the quality of education. To improve the quality of education, the government needs to focus on teachers' competencies, assuring teacher education programs' quality. Teacher education programs are supporting pillars in the system of education. Teacher education programs include professional development of teachers before services like B. Ed, M. Ed, and BS Education etc. and after joining service like induction training. In Pakistan, teacher education programs are offered from 6 months to 4-year programs with separate terms and conditions for each program or entry-level.

All the teacher education programs are compulsory professional qualification for teachers, but 16year education is considered a professional and academic qualification. With these compulsory teacher education programs, academic qualification is also a necessary part of the recruitment process. Different academic qualifications are offered in school subjects for the different levels of teaching, but now minimum sixteen-year qualification is compulsory in the school subjects to teach (All Answers Ltd, 2019). Therefore, there are trained teachers in schools, and PhDs have a chance to work with them.

Through the present research, the researchers are interested in studying this phenomenon and aimed to share the findings with the government authorities for addressing the challenges of $\mathrm{PhD}$ working in schools. The government of Pakistan can use the present study's findings for further improvements and developments in the education sector. The findings of this study could be helpful for policymakers and the school education department. It might be helpful for both the curriculum developers to uplift the system of education. In Pakistan, at the federal level, Federal College of Education (FCE) and the provincial level Quaid-e-Azam Academy for the Educational Development (QAED) are working on teacher education programs. The results of the study would also be helpful for both of the education agencies.

\section{Purpose and Main Question of the Study}

The teachers who possess a PhD degree, one of the highest qualifications in academics and on the other hand, the teachers working in schools with a primary or minimum level of required academic and professional qualification can have different teaching experiences in schools. Therefore, there is a need to study the lived experience, insight and feelings of $\mathrm{PhD}$ degree holder teachers who are the main focus in this phenomenon. The study's purpose is to have a phenomenological understanding of working at a school with the highest qualification that is meant for researching in higher education institutions rather than teaching in schools. Thus, the study's primary research question is: what are the expectations and experiences of $\mathrm{PhD}$ teachers working in a challenging school environment in the province of Punjab, Pakistan? Understanding the lived experiences of $\mathrm{PhD}$ teachers working in schools is very important in the present study because they can be used for further improvements and development in the education sector.

\section{Methods}

Qualitative research is usually used in social sciences with the focus of collecting extensive and indepth non-numerical data, exploring real meanings of life and investigating a research study at the micro-level through an inductive approach of exploration (Creswell, 2018). The researchers selected a phenomenological study design to have an in-depth understanding of participants' insight into the phenomenon and explore the lived experiences of $\mathrm{PhD}$ degree holder teachers working in the school education department.

\section{Participants}

All the PhD degree holder teachers working in the School Education Department (SED) in Punjab, Pakistan, constituted the population for this study. The study participants were scattered in the 
whole province and were not readily available and accessible. The snowball sampling was found an appropriate technique to approach the participants. This sampling is a form of purposive sampling in qualitative research that "typically proceeds after a study begins and occurs when the researcher asks participants to recommend other individuals to study" (Creswell, 2018). It is difficult to approach or locate participants or informants for conducting interviews because they are not available at a particular locale. The researchers contacted a $\mathrm{PhD}$ degree holder teacher known to them who was working in the school education department and searched for the other participants following the recommendation of the previous participants. Each participant gave the other ones the contact details, and the process continued until the data saturation. The detailed description of eleven selected participants with their gender, age group, $\mathrm{PhD}$ degree awarding institution and discipline of the PhD degree is given in table 1 below:

\section{Table 1}

Participants of the Study

\begin{tabular}{|c|c|c|}
\hline Characteristics & Description of Characteristics & $\begin{array}{c}\text { No. of } \\
\text { Participants }\end{array}$ \\
\hline \multirow[t]{2}{*}{ Gender } & Male & 09 \\
\hline & Female & 02 \\
\hline \multirow[t]{3}{*}{ Age } & Less than 40 years & 03 \\
\hline & $40-50$ years & 06 \\
\hline & Above 50 years & 02 \\
\hline \multirow{11}{*}{$\begin{array}{c}\text { PhD degree } \\
\text { awarding } \\
\text { Institute/Univers } \\
\text { ity }\end{array}$} & Bahauddin Zakariya University Multan (BZU) & 01 \\
\hline & Islamia University Bahawalpur (IUB) & 01 \\
\hline & International Islamic University (IIUI) & 01 \\
\hline & Government College University Faisalabad (GCUF) & 02 \\
\hline & National College of Business Administration and & 01 \\
\hline & Economics & 01 \\
\hline & University of Punjab (PU) & 01 \\
\hline & The University of Education, Lahore (UE) & 01 \\
\hline & Imperial College of Business Studies (ICBST) & 01 \\
\hline & Lahore College for Women University (LCWU) & 01 \\
\hline & National University of Modern Language (NUML) & \\
\hline \multirow[t]{9}{*}{ Subject } & Arabic & 01 \\
\hline & Biology & 01 \\
\hline & History & 01 \\
\hline & Education & 02 \\
\hline & Special Education & 01 \\
\hline & Statistics & 01 \\
\hline & Islamic studies & 01 \\
\hline & Urdu & 02 \\
\hline & Biotechnology & 01 \\
\hline
\end{tabular}

\section{Data Collection}

In the present research, the researchers selected the interview as a tool or instrument for data collection. In qualitative research, specifically in phenomenological research design, we collect real-life experiences, and interviews are among the best skills to collect data on real-life experiences (Creswell, 2018; Gilani et al., 2020). For validation of the interview guide, the researchers prepared an interview guide keeping in view the purpose of the study and principal research question, improved it by reviewing the relevant literature and discussing with the interviewees while conducting interviews for validation. Some of the questions asked from the participants include: How is it like for you to be a $\mathrm{PhD}$, working as a school teacher? You are one of the most qualified teachers in the school; what are your experiences and expectations from the 
school and education authorities? What is the nature of your relationship with school communities? What challenges do you face being a $\mathrm{PhD}$ degree holder teacher?

\section{Analysis of the Interviews}

Data analysis and interpretation enables a researcher to derive insights from the participants' perspectives and experiences by employing curiosity, open-mindedness, and empathy to listen interviewees' point of view in their natural settings to identify how their experiences and behaviours are shaped by the context of their social, cultural, economic and historical world (Creswell, 2018). Philosophical, theoretical, literary and interpretive lens is involved in shaping the knowledge. The use of subjective information from a first person's experience is associated with phenomenological analysis to identify core structures and features of human experience. The phenomenological analysis aims to explore, describe and interpret the meanings and nature of the experiences (Gilani et al., 2020).

In the present study, the researchers grounded their stance in the lived experience of the participants' relationships and language and their interpretation of the phenomenon because interpretation and meaning-making of the experience is fundamental to phenomenological inquiry (Tuffour, 2017: Waheed et al., 2019). The researcher analyzed and interpreted the collected data with the help of phenomenological analysis. The researchers coded the data through selective and highlighting approaches while going through each line of the transcript, developed categories, subthemes and themes from the collected data based on similarities and differences found in the interview transcripts.

\section{Results of the Study}

The following themes emerged as a result of the analysis of interview transcripts.

\section{Relationships with School Community}

The school community consists of students, teachers, heads and supportive staff. PhD degree holder teachers' interaction and relationships with students and teachers is very vital. Most PhD teachers reflected that dealing with student matters is not the same for all the teachers. Every teacher has a different way to deal with students. The $\mathrm{PhD}$ degree holder teachers were very interactive and had good relationships with their students, and in response, the students were also very cooperative, obedient and exhibited good manners. A PhD teacher remarked that, "Students feel proud while studying under my guidance. They consider me not only a teacher but also a mentor. That is why students like to discuss their real-life problems with me."

A PhD teacher was attached mentally and spiritually with the students and had given them independence and a friendly environment that led them to ask questions freely. The teachers had come up to students' level to create such a friendly and conducive learning environment. It was noticed that PhD teachers quickly understand and cope with students' situations. A common statement that emerged from most of the PhD teachers was that the students liked them and they were influenced by them due to their confidence, personality, mannerism, democratic and cooperative behavior, listening and answering all the questions from the students, including very simple or basic questions and positive reinforcement from them.

According to PhD teachers' point of view, the level of knowledge created a difference, but no personality clash or jealousy was observed with any of their non-PhD colleague based on qualification. Instead, there was an environment of discussions and cooperation between the two in the school's staff-rooms. $\mathrm{PhD}$ teachers wanted to extend equal treatment with non- $\mathrm{PhD}$ colleagues in all respects like honour, workload and any other academic or professional benefit. 
Non-PhD teachers made a consultation with the $\mathrm{PhD}$ teachers about life and routine academic matters for their opinion. It helped to create a cooperative environment among teachers in the school without any discrimination of academic qualification. Among other colleagues, $\mathrm{PhD}$ teachers were usually silent and did not show any dominant behaviour towards their colleagues. One of the teacher participants of age 34 years with a service length of eight years commented that "personality is reflected from one's behaviour; if you are jealous of others, you will also observe it in others".

The participants of the study did not appreciate school heads' relationships with $\mathrm{PhD}$ teachers. Most PhDs had a conflicting point of view, and they were against their heads' autonomous and autocratic behaviour. Nevertheless, some of the interviewees described that they had good communication with their heads. Overall, all the PhDs recognized their heads' importance and value and gave them respect and supported in administrative affairs. A research participant of age 50 years who was a subject specialist of education commented that "head deals categorically by placing the right person at the right place and time." The seat of heads in school is essential and should be compromised regarding merit issues. Heads usually performed well who are appointed on merit, which is further based on skills and qualification.

The participants' important statements exploring the theme of "Relationships with School Community" are given in Table 2.

\section{Table 2}

Statements of Participants on Relationships with School Community

\section{Theme: Relationships with School Community}

"Students feel proud while studying under my guidance. They consider me not only a teacher but also a mentor. That is why students like to discuss their real-life problems with me."

"Personality is reflected from one's behaviour; if you are jealous of others, you will also observe it in others".

"The school head deals categorically by placing the right person at the right place and time."

\section{PhD Teachers' Expectations}

Thinking to be 'different' from others may urge someone to have ordinary or extraordinary expectations. Hundred per cent fulfilment of these expectations cannot be assured from the school or education authorities' concerned persons. $\mathrm{PhD}$ teachers also had certain expectations from their students, colleagues, teachers, and heads, described in the following sub-themes.

\section{Expectations from students and colleagues}

The study participants remarked that they expect to see their students the best citizen in the country rather than pass a class and attain good grades. Another thing is respect and positive behaviour of students towards their elders in the society, the class fellows and their teachers. Positive change is necessary for the students, teachers and parents in society. One of the $\mathrm{PhD}$ teachers of age 50 who was teaching in a public school for the last 27 years expected from their students that "they should be a hard worker and serve their families and society after the school time." On the other hand, a young female $\mathrm{PhD}$ teacher wanted that "their students should be curious about learning new things". Most of the PhD teachers wanted to see their students at good positions in society. They wanted to make their students a role model in society.

Teachers make groups in schools according to their ideology and thinking. Some of the PhDs described that it is observed that a $\mathrm{PhD}$ teacher was found to be disciplined, cooperative and in 
proper dress code when he works with other teachers. According to a participant having more than ten publications and was teaching in a school "with a lot of respect from other teachers to a PhD teacher, a usual question to a PhD teacher raised by other teachers was about their qualification path, hardships or success stories". Other teachers working with $\mathrm{PhD}$ teachers in schools should also increase their qualification. One of the female $\mathrm{PhD}$ teachers teaching in a higher secondary school uncovered that "most of their colleagues are passive in schools whereas a $\mathrm{PhD}$ teacher was actively participating in solving difficult tasks".

\section{Expectations from Education Authorities}

Some of the $\mathrm{PhD}$ teachers did not like school heads who are academically strong and skilled in having good communication with all teachers. Some school heads did not like PhDs, and they felt jealous, fell in inferiority complex and created difficulties for $\mathrm{PhD}$ teachers instead of supporting them, especially during the data collection stage of their research work. Some interviewees described that school heads should also focus on increasing their qualification and professionally developing themselves. Other interviewees expressed that it is the heads of the institute and higher education authorities' responsibility that they should make plans to tackle and smooth the teaching and learning process in schools. There should be no favouritism; school heads should have vital patience and analytical skills to manage the school team.

Governance is an art to manage people and resources, and it is an integral part of any management body or system. In the present research, good relations were not observed between PhD teachers and higher management authorities who remained in contact with the school. One of the major causes of this conflict was clerical issues like delay in application processing for higher qualification approval, leave matters and higher qualification benefits that needs forwarding, attestation and verifications of degrees. Sometimes higher authorities exempted PhD teachers from duties like examination duties and other official matters. Most PhD teachers wanted that merit not be bypassed in any case like recruitments, further appointments, and promotions.

\section{Expectations for Professional Development}

Professional development and empowerment of teachers is also an important factor in the school education sector. A PhD teacher working in a public school elaborated that "Higher authorities are doing a great job, but there is a need to do something for teachers' professional development." During the present research, there was no particular plan identified for the professional development of $\mathrm{PhD}$ teachers. Generic pre-service and in-service teacher education programs were available for all teachers. One of the female $\mathrm{PhD}$ teacher participants of this research recommended that "teacher training and/refresher should be planned once after six months to cope with the issues in the system and consideration for the effective learning environment."

Over time, school education sector reforms will be essential to facilitate this society with the latest innovation and research. Nevertheless, no particular utilization of $\mathrm{PhD}$ teachers regarding school development and improvement was observed during this research. Most of the research participants wanted reforms in schools, including the use of technology. Laboratory facilities in schools are not up to the mark and need improvement.

The participants' important statements exploring the theme of "PhD Teachers' Expectations" are given in Table 3.

\section{Table 3}

Statements of Participants on PhD Teachers' Expectations 


\begin{tabular}{|l|}
\hline Theme: PhD Teachers' Expectations \\
\hline "Most of their colleagues are passive in schools whereas a PhD teacher was actively \\
participating for solving difficult tasks". \\
"A usual question to a PhD teacher raised by other teachers was about their qualification \\
path, hardships or success stories". \\
"Higher authorities are doing a good job, but there is a need to do something for the \\
professional development of teachers." \\
"Teacher training and/refresher should be planned once after six months to cope with the \\
issues in the system and consideration for an effective learning environment." \\
\hline
\end{tabular}

\section{Challenging School Environment}

Many challenges are faced by $\mathrm{PhD}$ teachers working in schools, such as they have to work on lowlevel scales and pay packages. People kept asking them which financial benefits they received after completing a $\mathrm{PhD}$ degree while spending a lot of money and time. Some $\mathrm{PhD}$ teachers also felt stuck in schools with no growth due to procedural delays in regularization, promotions, financial benefits, and service structure issues. Ultimately, the decrease in motivation level was continuing. Reducing the contract period of service, delay in teachers' regularity, promotions and leave issues are common challenges faced by most of the teachers, including PhD teachers. A lack of research grants, scholarship opportunities and new jobs in higher education institutions were the main challenge for PhD teachers. These factors hit the working and satisfaction of teachers badly, and they felt stuck.

Another reason explored from research participants about PhDs' performance is that they faced problems during teaching to lower grade students. They were not mentally prepared regarding students' aptitude and attitude. Financial constraints and a lack of opportunities to teach in higher educational institutions pushed them to work in schools. PhD teachers were facing a lack of resources as another barrier to implementing ideas in schools to increase their students' understanding.

It was explored during the interviews with research participants that $\mathrm{PhD}$ teachers could be helpful and may provide support to the government and school education department (SED). They can be useful regarding teacher training programs, conduction of exhibitions, curriculum development, textbook development and initialization of conferences on school education reforms and improvements. The research participants agreed that it is necessary to manage the maximum utilization of $\mathrm{PhD}$ teachers working in schools according to their specialities with appreciable remuneration.

The school education sector is always challenging due to its workforce and a large circle in the community. It is one of the biggest employers in a country with a lot of customers and employees. It makes this sector's environment challenging. Some PhDs also described the challenging environment of schools. The $\mathrm{PhD}$ teachers confronted with such challenging teaching, and they faced the problems with patience. Accepting the challenges, they handled the different level of IQs in one class.

Once there was an issue of less human resources in the school. A master degree holder or non-PhD teacher of English language subject was on leave due to PLT (Promotion Link Training) then a $\mathrm{PhD}$ teacher of other subject assigned the task to handle the class and teach them the English language whereas his subject was not English. After a month, the English teacher came back. He was surprised to see that the entire class was under the "influence" of the PhD teacher despite not being a subject specialist in the English language. In another situation, when a $\mathrm{PhD}$ teacher of the Arabic language was assigned to improve the poor results of the students of Urdu language at a 
secondary level after his posting in a school due to promotion, the $\mathrm{PhD}$ teacher accepted this new challenge to teach Urdu subject and produced outstanding results in the academic year.

Research participants agreed that teaching and developing an understanding of students were two separate things. To overcome this challenge of building a strong understanding and personality of a learner, $\mathrm{PhD}$ teacher usually takes a class from a lower academic grade and continues to teach this class for many years until completing that batch's schooling.

\section{Findings and Discussion}

Without research and innovation, the teaching and learning process is discouraging in view of an interviewee who remarked that "My school is doing nothing at all in research. They spend as little time as possible on the professional development of teachers." Similar to this finding, it was explored that, "Dedicated hours for the professional development of teachers are not utilized. Meanwhile, nothing is done with research" (Bakx et al., 2016).

A school is a place where students learn such concepts which are long-lasting. Such concepts create strong effects on their lives because there is a more minor issue of grades or marks than higher academic and critical thinking. A teacher with solid concepts and an interactive personality style is more valuable for teaching in schools. This factor adds to the value of $\mathrm{PhD}$ teachers in the school education system.

$\mathrm{PhD}$ Teachers are good in relationship within the whole school community, including students, teachers, and heads. Students and teachers are in a struggle to follow the unique personality of $\mathrm{PhD}$ teachers. They are interested in the success stories of PhD teachers. Higher academic qualification like a $\mathrm{PhD}$ degree is always a source of attraction, inspiration and motivation for others within the school community.

A negative perception to become a high school teacher after PhD was also present in the community. This perception is considered a failure of a $\mathrm{PhD}$ person who becomes a teacher in a school. Sometimes, this negative perception is at the climax and creates hesitation for a PhD teacher, and he avoids giving his introduction as a school teacher in front of a supervisor, thesis committee, and career workshops. This perception is not constant in the whole world; like in Finland, it does not prevail, but in the United States, it is at a remarkable level (Doyle \& Vale, 2013). The present study was conducted in Pakistan, and negative perceptions about PhD teachers prevailed here, but $\mathrm{PhD}$ teachers were not so hesitant or a victim of inferiority complex.

$\mathrm{PhD}$ teachers are coping with the challenging environment of schools. They felt a very positive change in their teaching skills that includes methodology, classroom management, assessment and interaction with students in schools after completing a PhD degree. PhD teachers are now on the way from excellence to exceptionality. They were academically at excellence and wanted to hold another peek of expectations. Academic excellence is a positive factor for all, but financial expectations may create problems and conflicts in the system. Future challenges and perspectives attached with the $\mathrm{PhD}$ teachers may help policymakers to adjust their proper utilization in the circle of the school education system.

\section{Conclusion}

It was fortunate or unfortunate that PhDs were working as teachers at a different level of schools. It may be predicted that many $\mathrm{PhD}$ degree holders will be ready to join the school as teachers in the next recruitments and many PhDs are in the process of completing their PhDs. Nevertheless, their presence is significant and affects the quality of teaching and other aspects of school education, including administration and policymaking. It is concluded that $\mathrm{PhDs}$ had a healthy and supportive relationship with the school communities, including students, teachers, and other 
administrative staff. Nevertheless, it was perceived from participants' experiences that they did not find school heads very supportive and helping persons. The PhDs had expectations from students, teachers and heads of the school for their professional development and school improvement. They were facing a challenging school environment but working and surviving with resilience.

\section{References}

All Answers Ltd. (2019, December 6). Comparison of Teacher Education Programmes in Pakistan \& UK. https://ukdiss.com/examples/analysis-of-teacher-education.php.

Bakx, A., Bakker, A., Koopman, M., \& Beijaard, D. (2016, August 13). Boundary crossing by science teacher researchers in a PhD program. Teaching and Teacher Education, 60,76-87.

Craig, C. J. (2009). Teacher research and teacher as researcher. International Handbook of Research on Teachers and Teaching, 61-70.

Creswell, J. W. (2018). Research design: Qualitative, quantitative, and mixed methods approaches. (3rd ed.). Thousand Oaks, CA: Sage.

Doyle, K. M. H., \& Vale, R. D. (2013, November). Creating opportunities for science PhDs to pursue careers in high school education. Mol Biol Cell, 24(21), 3292-6.

Gilani, N., Waheed, S. A., Hussain, B. (2020). Multiculturalism and integration: Challenges, strategies and prospects of students' integration in educational environment and society. Global Social Sciences Review, 5(2), 174-181.

Gilani, N., Waheed, S. A., \& Shaheen, A. (2020). Making a debut in teaching: Uncovering prospective teachers' first-time teaching experiences in schools. Universal Journal of Educational Research, 8(11), 5443-5452. DOI: 10.13189/ujer.2020.081147.

Gilani, N., Waheed, S. A., \& Ullah, A. (2020). Students' experiences of failure to get admission in desired medical degree programs and their choices of alternative degrees. International Review of Social Sciences, 8(11), 24-37.

Government of Punjab, School Education Department. (2020). https://schools.punjab.gov.pk/ourfunctions

Tuffour, I. (2017, July 29). A Critical Overview of Interpretative Phenomenological Analysis: A Contemporary Qualitative Research Approach. Journal of Healthcare and Communications, 2(52).

Tuhus-Dubrow. (2013). The repurposed Ph.D. New York Times. Retrieved from http://www.nytimes.com/2013/11/03/education/edlife/finding-life-after-academia-andnotfeeling-bad-about-it.html

Waheed, S. A., Gilani, N., Shoukat, L. (2019). The study abroad decision: A qualitative case study of Pakistani doctoral students. Global Regional Review, 4(4),328-335.

Wing, M. R. (2018, November 7). High School Teaching Is the New Tenure-Track Job. https://eos.org/opinions/high-school-teaching-is-the-n 